\title{
AS PREFEITAS EM PERSPECTIVA: REPRESENTATIVIDADE FEMININA NA POLÍTICA PARAIBANA
}

Falar da participação política da mulher exige, previamente, alguns lembretes no tocante às condições históricas desta participação. Afinal, trata-se de um processo de constituição da cidadania para amplas camadas da população, numa república que já viveu demasiado tempo sob a tutela das forças armadas e de oligarquias retrógradas [...]. MARIA L. MORAES ${ }^{l}$.

\section{Dayanny Deyse Leite Rodrigues ${ }^{2}$}

Resumo: Consolidado o direito institucional do voto feminino a mais de oito décadas, ainda nos deparamos com uma reduzida representatividade das mulheres na política partidária, se comparado ao número de homens presentes no mesmo espaço. Estudos recentes como os de Avelar (2001), Garcia (2005), Rabay e Carvalho (2010), apontam um aumento da participação feminina na política eleitoral, principalmente a partir da década de 1980. Dentre as esferas institucionais da política, a municipal é aquela que apresenta o quantitativo mais elevado da representatividade feminina. Por diversos fatores o poder municipal se mostra mais acessível às mulheres. Dialogando com uma nova perspectiva de História Política, compreende-se que falar sobre as prefeitas, seja em âmbito nacional, regional ou local, se configura como algo desafiador e necessário na conjuntura atual. A Paraíba, estado brasileiro que proporcionalmente elegeu o maior número de mulheres nas eleições municipais de 2012, carrega em sua trajetória política, aspectos singulares. Dessa forma, este estudo tem por objetivo analisar a representação feminina no executivo municipal paraibano, tendo como base as prefeitas eleitas nas eleições de 2008 e 2012 respectivamente, pontuando aspectos que demonstram permanências de práticas e características políticas, assim como novidades portadas por algumas delas. Para a análise, foram utilizados dados disponibilizados pelo Tribunal Superior Eleitoral e Tribunal Regional Eleitoral, bem como uma releitura da bibliografia produzida sobre o tema. Para pensar essa representação, buscou-se responder alguns questionamentos, tais como: quem foram as prefeitas da Paraíba eleitas nos dois pleitos estudados? Quais as características socioeconômicas e demográficas dos municípios que as elegeram? Quais os seus partidos? Quais suas relações de parentesco? Qual a faixa etária e grau de escolaridade delas? Quais as experiências anteriores à política? Após as análises, observou-se que o quadro de gestoras é composto majoritariamente por mulheres com faixa etária acima dos 30 anos de idade, não ultrapassando os 60, maioria casada e possuidora de ensino superior completo. Destaca-se também que as mesmas governam, em especial, municípios menos desenvolvidos economicamente, emancipados recentemente, e com uma população inferior a 10.000 habitantes, tendo a maioria sido eleitas por partidos de direita e do centro.

Palavras-chave: Representatividade; Mulher; Política Partidária.

Summary: Consolidated the international right of female vote since eight decades ago, we still see a reduced representation of women in party politics, if we compare that with the number of men in the same place. Recent researches, like Avelar (2001), Garcia (2005), Rabay e Carvalho (2010), show an expansion in the female participation in the electoral politics, principally after the 1980's. Into the institutional spheres of politic, the municipal is which presents que most expressive number of women. Because that, the municipal power is most accessible for the women. To talk with that new perspective of the Political History, we know that when we tell about the women mayors, into the national, regional or local spheres, it can be challenging, but important in the actual conjuncture. The Paraíba, Brazilian state which proportionally elected the higher number of women in the municipal elections of 2012 , had in its political trajectory singulars aspects. In this way, this research aims analyses the female representation in the municipal executive power of Paraíba, seeing the women mayors in the elections of 2008 and 2012 with the aspects which show the permanency of practices and political characteristics, and which presents the changes too. For the analysis, we use the data available by Higher Tribunal Electoral and the Regional Tribunal Electoral, as well as the revision of the literature produced of this theme. To think this representation, we choose answer some questions: who were the women mayors of Paraíba elected in both elections studied? Which social, economic and demographic characteristics of this cities which elect them? Which was their parties? Which were their family relationships? Which were the age and time of studies? Which were their before experiences? After the analysis, we can see some results: the women mayors were priority women older than 30 years old and younger than 60 . They were married and they completed the college. That women govern in special the small cities, recently emancipated and with a population shorter than 10.000 inhabitants. The majority was elected by the parties of right and center.

Key-Words: Representation; Women; Party Politics.

1 MORAES, Maria L. Quartim de. Mulheres em movimento: o balanço da década de mulher do ponto de vista do feminismo, das religiões e da política. São Paulo: Nobel/CECF, 1985, p. 51

${ }^{2}$ Discente do Programa de Pós Graduação em História da Universidade Federal da Paraíba. Pesquisadora da temática Mulher e Política. E-mail: dayannydeyse@hotmail.com 
Resumen: Consolidado el derecho institucional de votación feminine a más de ocho décadas, todavía se enfrenta con una reducida representación de la mujer en la política, si se compara con el número de hombres presentes en el mismo espacio. Estudios recientes, como el de Avelar (2001), García (2005), Acquario y Carvalho (2010), sugieren un aumento de la participación femenina en la política electoral, especialmente a partir de la década de 1980. Entre los ámbitos institucionales de la política, el hall es uno de los que presenta el nivel cuantitativo de la representación de la mujer. Por varios factores, el poder municipal se manifiesta más accesibles a las mujeres. Hablando con una nueva perspectiva de la historia política, se entiende que hablar de los alcaldes, ya sea a nivel nacional, regional o local, si está configurado como algo desafiante y necesario en la situación actual. El Paraíba, estado brasileño que elegido proporcionalmente el mayor número de mujeres en las elecciones municipales de 2012, lleva en su carrera política, aspectos naturales. Por tanto, este estudio pretende analizar la representación de la mujer en el ejecutivo municipal Paraiba, tomando como base los alcaldes elegidos en las elecciones de 2008 y 2012, respectivamente, anotando los aspectos que demuestran estancias de prácticas y políticas específicas, así como nuevas persianas en algunos de ellos. Para el análisis se utilizaron los datos proporcionados por el Tribunal Supremo Electoral y el Tribunal Electoral Regional, así como una nueva lectura de la literatura producida sobre el tema. Pensar de esta representación, hemos intentado dar respuesta a algunas preguntas, tales como: ¿Quienes fueron las prefect de Paraíba elegidos sobre dos peticiones estudiadas ¿Cuáles son las características demográficas y socioeconómicas de los municipios que si es elegido ¿Cuáles son sus partes ¿Lo que sus relaciones de parentesco ¿Cuál es la edad y el nivel de la educación de ellos ¿Cuáles son las experiencias previas a la política. Tras el análisis, se observó que el activo está compuesto principalmente por mujeres mayores de 30 años de edad, no superior a 60, la mayoría casados y con educación superior. Es también digno de mención que regulan, en particular, los municipios menos desarrollados económicamente, recién emancipados, y con una población de menos de 10.000 habitantes, habiendo sido elegidos por la mayoría de los partidos de derecha y el centro.

Palabras-clave: representatividad; Mujer; La política de partido.

Natural do Rio Grande do Norte, Alzira Soriano de Souza foi a primeira prefeita a constar na história política brasileira, eleita em 1928 na cidade de Lages, Rio Grande do Norte. Em discussão no país a alguns anos, o direito ao voto para as mulheres foi conquistado em 1932. O Partido Republicano feminino, a Federação Brasileira pelo Progresso Feminino e suas entidades estaduais, foram espaços de grande concentração de debates e lutas em prol de demandas femininas. Apenas 30 anos depois da primeira prefeita ser eleita, outra mulher exerceria o mesmo cargo no Brasil. Em 1958, Aldamira Guedes foi eleita prefeita de Quixeramobim, no Ceará. "Na Paraíba, a primeira mulher a conquistar o cargo de prefeita foi Dulce Barbosa, na década de 1960, no município de Queimadas" (RABAY; CARVALHO, 2014, p. 03). Crescendo de forma gradual mas não igualitária, o total de mulheres hoje no poder executivo municipal é de 662 em todo o país.

No entanto, vale destacar que parte considerável da historiografia tradicional desconsidera todo esse processo de luta e conquista, assim como negligencia as diversas atuações femininas para além do espaço privado, tido como seu de forma naturalizada e segregada no imaginário social. Devido a reconfigurações ocorridas no interior do fazer historiográfico, as quais serão apresentados alguns pontos no decorrer do texto, estudos recentes já levam em consideração diversas atuações femininas junto à política, e apontam a sua discrepante participação quando comparado à masculina na mesma (RABAY; CARVALHO, 2010).

Dialogando com uma nova perspectiva de História Política, compreende-se que falar sobre as prefeitas, seja em âmbito nacional, regional ou local, se configura como algo desafiador e necessário na conjuntura atual, tendo em vista que é a esfera da política partidária que apresenta a maior representatividade feminina. A Paraíba, estado brasileiro que proporcionalmente elegeu o maior número de mulheres nas eleições municipais de 2012, carrega em sua trajetória política aspectos que merecem ser compreendidos enquanto formadores de uma cultura política brasileira.

Dessa forma, esse estudo tem por objetivo analisar a representação feminina no executivo municipal paraibano, tendo como base as prefeitas eleitas nas eleições de 2008 e 2012, respectivamente, pontuando aspectos que demonstram permanências de práticas e características políticas, assim como novidades portadas por algumas delas. Para a análise, foram utilizados dados disponibilizados pelo Tribunal Superior Eleitoral e 
Tribunal Regional Eleitoral, bem como uma releitura da bibliografia produzida sobre o tema. Para pensar essa representação, buscou-se responder questionamentos, tais como: quem foram as prefeitas da Paraíba eleitas nos dois pleitos estudados? Quais as características socioeconômicas e demográficas dos municípios que as elegeram? Quais os seus partidos? Quais suas relações de parentesco? Qual a faixa etária e grau de escolaridade delas? Quais as experiências anteriores à política?

Como mencionado, o trabalho terá como base teórica a História Política. Como afirma Rémond (1996), a nova história política se apodera de outros problemas que não lhe dizia respeito anteriormente, como a preocupação com o estudo da participação na vida política e seus processos eleitorais, integrando todos os seus atores, deixando de lado o caráter elitista e individualista da antiga história política (RÉMOND, 1996 p. 24). Para ele, o político não é um fato isolado, tampouco imutável. Deve ser analisado e inscrito na longa duração. Este estudo caminha baseado nessa perspectiva, dando espaço a mulher enquanto sujeito histórico, mas por muito tempo silenciado pela história política nacional e em especial do estado paraibano. O panorama atual da produção historiográfica brasileira parece ter mudado significativamente, demonstrando a presença desses novos sujeitos, aderindo as discussões teóricas e sugerindo a inserção de novos conceitos bem como de outras abordagens. Dos anos de 1960 - 70 em diante, estudos envolvendo a mulher enquanto sujeitos históricos vêm sendo elaborados, principalmente nos interior das universidades.

Também foi a partir dessas duas décadas que estudos de história política passaram a se reconfigurar, voltando novamente aos pilares da produção historiográfica contemporânea. Como afirma Silveira (2010), soberana até o início do século XX, a história política foi fortemente atacada e rejeitada pelos Annales ${ }^{3}$ a partir dos anos de 1930. Apontada como elitista, narrativa e linear, a este tipo de fazer histórico teve que ser repensada para "retornar" ao centro das discussões historiográficas. Os Annales defendiam a ideia de uma História Total e globalizante. "Foi contra esse estado de coisas, contra a hegemonia do político, herança de um longo passado, que, em nome de uma história total, uma geração se insurgiu e fez-se uma revolução na distribuição do interesse" (RÉMOND, 1996, p. 15).

Rémond (1996) demonstra que uma das primeiras "vítimas" nesse processo de reconfiguração histórica encabeçada na França pelos Annales, foi a história política, que segundo os que a negavam, carregava características divergentes daquelas que deveriam portar um tipo ideal de história. Essas novas orientações na perspectiva histórica caminhavam dialogando com o ambiente social, político e ideológico europeu, que passara a direcionar seus estudos para as massas. Atacada e rejeitada por algumas décadas, a história política passou por um processo de renovação que começara a se organizar também na França, no final da década de 1960, especialmente na Universidade de Paris-X- Nanterre e no Instituto de Estudos políticos de Paris, buscando superar as críticas que lhes foram proferidas, assim como se estabilizar como perspectiva histórica coerente com uma nova realidade vivenciada, principalmente após a década de 1980. "A história de fato não vive fora do tempo em que é escrita, ainda mais quando se trata da história política: são variações são resultados tanto das mudanças que afetam o político como as que dizem respeito ao olhar que o historiador dirige ao político. Realidade e percepção interferem" (RÉMOND, 1996, p. 22).

Passado por esse momento de reajuste, a História Política, também chamada de Nova História Política, busca estudar todos os espaços nos quais o poder circundam, não mais apenas acreditando que este encontra-se unicamente nas forças institucionais, mas se faz presente de forma diluída nas mais diversas esferas da sociedade e entre os diferentes agentes que os compõem. Assim, o estudo de novos sujeitos passou a ser uma possibilidade, e nessa perspectiva, compreender a atuação das mulheres na política partidária se apresenta

${ }^{3}$ Escola historiográfica francesa que combateu o fazer histórico entendido com Tradicional, Metódico/Positivista. A História Política estava entre estas, e foi assim, criticada por essa escola e seus seguidores, tendo Marc Bloch, Fernand Braudel e Lucien Fevre como nomes mais conhecidos. 
como um exercício necessário e árduo, e além de tudo, pertinente ao ofício do historiador.

Fugindo do ideário de análise de acontecimentos curtos, ao analisarmos a representação feminina no poder executivo municipal paraibano, buscamos assim compreender como estas contribuíram e/ou se inseriram numa cultura política brasileira, emergente principalmente após o advento da república. A possibilidade de formulação e uso do conceito de Cultura Política pelos historiadores, foi possibilitada pela efervescente valorização da História Cultural, sob a percepção de que a cultura também determina o desenrolar dos acontecimentos. Segundo Motta (2009), o conceito de Cultura Política foi mais uma construção teórica formulada pelas Ciências Sociais que foi apropriada pelos historiadores, apontando mais uma característica do que conhecemos historiograficamente como Nova História Política, que consiste na aproximação e diálogo com outras áreas do conhecimento.

No primeiro artigo do livro "Culturas Políticas na História: novos estudos", organizado por Rodrigo Pato Sá Motta, o historiador, buscando elaborar uma síntese da história do conceito de cultura política, nos apresenta uma abordagem conservadora do referido conceito assumida pela sociologia americana lideradas pela psicologia de Verba e Almond. Em contrapartida, também explora uma abordagem mais pluralista, abordada pelos historiadores franceses, influenciados pelos conceito de cultura da antropologia, tendo como precursores Berstein e René Rémond. Motta (2009) ainda destaca que o tempo histórico próprio das culturas políticas é o da longa duração, no entanto, apesar de sua dimensão estrutural, elas são históricas, dinâmicas e variáveis. Ressalta a possibilidade do estudo centrado na presença de personagens individuais como inspiradores de culturas políticas, justificando que sua utilização não implica numa ruptura com a história social, nem busca construir mitos históricos.

Dessa forma, caminhando pelos labirintos dessa Histórica Política repensada e renovada, buscou-se, por meio deste estudo, contribuir com pesquisas referentes à participação feminina na política partidária, enfatizando sua atuação no âmbito do executivo municipal, espaço que carrega consigo inúmeras singularidades e particularidades que devem ser levadas em conta.

\section{As prefeitas paraibanas em foco: do teórico ao empírico}

Atualmente, a esfera municipal é aquela que apresenta o maior quantitativo participativo feminino, mesmo ela ainda representando uma minoria de mulheres. No que diz respeito ao resultado do pleito de 2012, Rabay e Carvalho (2014) apontam o seguinte:

\footnotetext{
Em termos relativos ao número de municípios, foi a Paraíba o estado brasileiro que mais elegeu mulheres para as prefeituras. Enquanto Minas Gerais possui apenas 8,3\% dos municípios governados por mulheres, São Paulo 10,3\% e Bahia 15,6\%, a Paraíba, como já foi dito, elegeu mulheres para a prefeitura de $22 \%$ do total dos municípios (RABAY; CARVALHO, 2014, p. 02.).
}

Se observada a participação feminina nos âmbitos nacionais e federais, essa sub-representação fica ainda mais evidente. Por diversos motivos o poder municipal é aquele que apresenta essa acentuada participação feminina. Como Blay (2015) destaca,

É inútil pensar-se que as mulheres eleitas para o governo municipal constituam um caso específico, particular. Ao contrário desta afirmação, cabe investigar como e porque o processo político brasileiro absorve a mulher na política local” (BLAY, 2015, p. 10).

Dentre uma infinidade de fatos, destacamos a proximidade entre "lar" e prefeitura. 
Por diversos motivos, o poder local tem sido pensado como um espaço privilegiado da participação feminina no campo político. A proximidade do lócus de atuação política (a prefeitura) do lar, permitindo a conciliação entre as obrigações políticas e as obrigações familiares, a percepção de que a edilidade demanda ações próximas às necessidades reprodutivas relacionadas à saúde, educação, limpeza urbana, e o questionamento corrente a respeito de uma dependência feminina em relação à família e aos esquemas político-familiares, são elementos que podem contribuir para uma percepção sobre a cidade como um espaço que demanda cuidados femininos, especialmente quando se trata das pequenas cidades do interior (RABAY; CARVALHO, 2014, p, 02).

A prefeitura se constitui nessa percepção como uma continuidade da casa, não quebrando com o tão estigmatizado binômio público versus privado. A atuação feminina no executivo municipal poderia ser caracterizada então como uma continuidade de sua ação no espaço privado, não representando de fato emancipação em termos de consciência e representação. Vale destacar que essa afirmativa não pode ser generalizada, mas apenas apontada como uma possibilidade de argumento, tendo em vista que se a prefeitura é o "passo inicial" para a entrada na política institucional, elas estando presentes nelas, já é um indicativo de que essa entrada já teve início. Em um reconhecido estudo sobre a temática, Lúcia Avelar (2001), destaca que,

O incremento das candidaturas femininas para os cargos municipais fica evidente. Na política local é mais fácil conciliar, um verbo crucial na vida de quase todas as mulheres. E, no caso, trata-se de conciliar vida profissional, vida familiar e vida política, três universos altamente envolventes e de múltiplas demandas. Esse aspecto tem sido menosprezado nas análises sobre a menor presença das mulheres na política, com raras exceções (AVELAR, 2001, p.69).

Avelar (2001) nos expõe um ponto bastante relevante, sendo a política partidária um espaço ainda considerado masculino, as mulheres que adentram este espaço tem que conciliar com outros afazeres, profissionais ou domésticos, ainda entendidos como de sua responsabilidade. Esse argumento é fortalecido pelos dados apresentados por Eva Blay (2015), referentes às eleições municipais da década de 1970. A socióloga destaca que no que diz respeito à experiência político eletiva, em cada 10 mulheres eleitas na década analisada, 7 nunca haviam sido eleitas anteriormente. Já entre os homens, 7 dos 10 já haviam se elegido em momentos anteriores. Isso demonstra que os homens eleitos já tinham de certa forma, uma carreira política consolidada, tendo eles a política por "profissão". Enquanto as mulheres, se apresentando em seu primeiro pleito, demonstram exercerem outras atividades profissionais até o momento da entrada na política. Muito se ouve falar em "aquele homem é político", "aquela mulher está na política". Dados e fatos se perpetuam, em entrevistas realizadas com algumas gestoras municipais paraibanas eleitas em 2008 e 2012, nas quais muitas delas reforçam essa ideia. "Minha profissão é "tal". Eu não sou política, eu estou na política".

Por outro lado, esse acesso via esfera municipal pode ser entendida como estratégia para aquelas que reconhecem que para sua ascensão no cenário político, a atuação no executivo municipal pode contribuir para o processo de constituição de seu capital político, pois, como afirma Bourdieu (2004), aqueles que não possuem um conhecimento peculiar, ou capital cultural que no meio político se torna capital político, estão cada vez mais fadados a delegar representantes aparentemente aptos, ou profissionalizados, à realização da chefia política. Ou seja, ou se tem o conhecimento necessário e pertinente ao campo político para poder nele adentrar e permanecer, ou lhes caberá o exercício de escolher seus representantes, que por ventura, devam ter determinados conhecimentos. Ainda de acordo com Bourdieu (2004), o processo de entrada e permanência na política é algo que está relacionada a adaptação a determinadas regras. Para ele portar certo tipo de capital político é fator essencial para a entrada de um indivíduo na política partidária. Dessa forma, entende-se que 
os indivíduos, por meio de seus vivencias/experiências, constituem seu capital político e adentram a referida esfera, sendo esse percurso, na maioria das vezes, iniciado nas esferas menores, por exemplo, é mais comum ser eleito vereador/a, depois prefeito/a, deputado/a, governador/, etc. Pressupõe-se que o acúmulo de capital político propicia essa ascensão política.

Outro ponto observado e que merece destaque é a diminuição do poderio político local, em detrimento do nível nacional e local. Iniciado com o movimento de 1930, o processo de centralização estatal acabou reduzindo o poderio local das diversas lideranças municipais. Isso não implica dizer que aqueles políticos de atuação local tiveram seu poder político extinto, mas que de certa forma, houve uma queda da autonomia até então vigente. Assim, nota-se um enfraquecimento do poder local em detrimento do poder central, estabelecendo os limites de atuação das lideranças locais. Blay destaca que "A prefeitura representa, no atual sistema político brasileiro, a instituição capaz de expressar o poder local” (BLAY, 2015, p. 15). Dessa forma, se o poder local diminuiu sua potencialidade política frente às demais esferas, as prefeituras passaram a ser espaços menos disputados pelas grandes lideranças políticas, que para se fazerem presentes nos patamares políticos, adentraram os esferas de maior notoriedade.

Entretanto, por menor que fosse seu significado, as lideranças coronelistas não estão dispostas a abandonar essa parcela do poder. Nesta circunstância, parecem que os homens foram destinados a cargos na esfera estadual e federal, e às mulheres do mesmo grupo social coube o exercício do poder local (BLAY, 2015 , p. 23-24).

O argumento apresentado por Eva Blay faz sentido, na medida em que boa parte das prefeitas eleitas pertencem a famílias políticas, biologicamente ou via matrimônio. O mesmo também ocorre com os homens destas mesmas famílias que se candidatam ao executivo municipal, e dão continuidade a carreira política nas outras esferas. Dessa forma, para eles a prefeitura é um estágio inicial no processo de adentramento e acessão na carreira política. Em contrapartida, muitas mulheres eleitas para o cargo de prefeitas, não ultrapassam essa esfera. Para Blay,

A tradição de dispor de todos os cargos políticos ocupando-os pessoalmente, indicando membros da família ou correligionários para preenche-los, constitui a forma tradicional de dominação do poder local. Por isso o 'chefe' político local procura criar, no interior de sua família nuclear ou extensa, uma predisposição para o desenvolvimento de carreiras políticas” (BLAY, 2015, p. 39).

Assim, conquistado o direito ao voto na década de 1930, momento de início da perda de preponderância política das lideranças locais, "Parece-nos que a participação política feminina surgiu muito espontaneamente nesse período em que o município deixou de interessar à política da camada dominante" (BLAY, 2015, p. 57). Nesse momento, percebe-se certa expansão e deslocamento desse poderio, antes centralizado principalmente na zona rural, as lideranças locais pensam estratégias para ampliar seu poderio, passando a atuar no meio urbano, e nas esferas políticas para além da municipal.

Corroborando com esse pensamento, Avelar (2001) destaca que a grande maioria das prefeitas brasileiras são eleitas nos pequenos e médios municípios nos quais as relações de poder permanecem sob poder das oligarquias, indicando essa presença feminina como uma possível estratégia de perpetuação de poder das grandes famílias na política local.

Um terceiro ponto que podemos apontar diz respeito ao menor poder econômico do Nordeste, se comparado a outras regiões do país. Pesquisas apontam que as mulheres se fazem mais presente nos municípios menos desenvolvidos economicamente. Dessa forma, o Nordeste é a região que mais elege mulheres 
para o executivo municipal desde a década de 1950. Blay (2015) aponta uma pesquisa (IBAM, 1975) realizada em 1958, que afirma que 5 mulheres foram eleitas prefeitas naquela época, sendo 4 delas em municípios do Nordeste. Em 1973 a mesma instituição teria feito outra pesquisa 3.950 municípios brasileiros, sendo 54 governado por mulheres. Blay aponta que são 60 mulheres eleitas em 1972. Grande maioria novamente eleita no Nordeste.

Outros estudos como os de Costa (1998), Avelar (2001), Garcia (2005), Rabay e Carvalho (2010), (2014), também destacam esse aspecto e discutem sobre algumas práticas políticas existentes no Nordeste, que podem contribuir para essa presença de mulheres na política local. Vale ressaltar que o Nordeste tem sua história política marcada pela presença de práticas coronelísticas e clientelísticas, alianças partidárias, bem como pela perpetuação de famílias no poder local.

A região nordeste, a mais pobre do Brasil, é marcada pelo estigma de ser uma região atrasada economicamente, assolada por secas e politicamente dominada por coronéis. A população nordestina vivem em condições de pobreza e desigualdade social, reflexo de um processo multissecular de exploração e concentração de renda, terra e poder político patriarcal, apresentando diversificadas formas de exclusão. Essas características conduziram a um modelo político baseado no clientelismo, na compra de votos, gerando relações de dependência de uma maioria extremamente pobre em relações aos chefes políticos locais. No nível municipal, essas tendências são acentuadas pela prevalência das relações familiares sobre o poder dos partidos (GARCIA, 2005, p.14).

Para além de se fazerem presentes pelo fato da região apontada ser menos desenvolvida, como hipótese, Garcia (2005) destaca que "no caso específico diante extrema pobreza do nordeste as mulheres aproveitam as brechas criadas nos controles patriarcais e conquistam alguns espaços de poder" (GARCIA, 2005, p.16-17). "No Nordeste, o número de prefeitas é maior que a média nacional. Em 1966, as nordestinas representavam 81,25\%das prefeitas" (RABAY E CARVALHO, 2010, p. 25). De acordo com Blay (2015), em 1972 das 60 prefeitas eleitas em todo Brasil, 47 delas estavam no Nordeste, o mesmo continuou ocorrendo nas futuras eleições. Em 1992 das 171 prefeitas eleitas em todo Brasil, 92 foram no Nordeste. Em 2000, das 318 eleitas, 147 na mesma região. Em 2012 das 670 eleitas, 289 são gestoras na região Nordeste. A esse respeito, Blay (2015) ressalta que "São as regiões de menor desenvolvimento econômico, menos urbanizadas e menos industrializadas as que mais elevam a mulher à chefia do poder local” (BLAY, 2015, p. 19).

Vale ressaltar que o Nordeste tem sua história política marcada pela presença de práticas coronelísticas e clientelísticas, alianças partidárias, bem como pela perpetuação de famílias no poder local. Como salienta a historiadora brasilianista Linda Lewin (1993) durante a Primeira República, a Paraíba foi comandada por famílias oligárquicas que se revezavam no poder, utilizando-se de diversas práticas como a violência e a fraude eleitoral. Segundo Lewin, a primeira oligarquia predominante na Paraíba foi a Machado-leal, que dominaria a política local até 1912. Após esse período a oligarquia epitacista teria acendido ao poder, permanecendo no mesmo por muitos anos, até 1930.

Assim, fica perceptível o caráter elitizado e oligárquico do processo eleitoral brasileiro, e em particular do paraibano. Historiadores como Carneiro (2009), Mello (1997), Gurjão (1999) e Lewin (1993), afirmam que durante a primeira República, a política paraibana foi dominada pelas famílias de Venâncio Neiva, Álvaro Machado, Walfredo Leal e Epitácio Pessoa, tendo o empreguismo, o nepotismo e o coronelismo como características marcantes do período. As oligarquias se revezavam no poder do estado, usando das mais diversas estratégias para se manter neste, incluindo as fraudes e a constante violência. De acordo com Mello, ( 1997), “em diversas situações eleitorais, as divergências políticas apenas configuravam o choque dos interesses familiares, tradição que na Paraíba, bem como no Brasil, o Império comunicou à República" (MELLO, 1997, 
p. 120).

Corroborando com o pensamento de Mello (1997), Gurjão (1999) ressalta que,

\begin{abstract}
Na Paraíba, durante a República Velha, as lutas entre as famílias foram uma constante. A corrupção e a violência caracterizavam as disputas entre as oligarquias situacionistas e oposicionistas nos municípios. Comumente coronéis mandavam seus cabras emboscar e agredir seus adversários; quando não se articulavam com bandos de cangaceiros para maior eficiência do serviço (GURJÃO, 1999, p. 56).
\end{abstract}

Finalizando, em partes, esse ponto da discussão, destacamos que buscamos aqui apontar alguns fatores que, de certa forma, justificam uma maior participação feminina na política municipal, apresentando algumas de suas características e práticas. Agora apontaremos alguns dados empíricos a respeito das prefeitas paraibanas eleitas em 2008 e 2012, e os discutiremos aos olhos da bibliografia relacionada e da perspectiva da História Política.

Para obtermos os resultados expostos e discutidos a seguir, foram analisadas as fichas de inscrição de candidatura de cada uma das prefeitas eleitas, tabelas com os resultados das eleições, na qual encontramos informações relevantes tais como o número exato de votos e a porcentagem de cada candidato, assim como a produção bibliográfica referente a temática que também discutiram as mulheres no poderio municipal, enfatizando outras temporalidades.

Na esfera municipal, segundo os dados do TSE e TRE, o número de prefeitas cresceu de 171, em 1993, para 505 em 2008 e 662 em 2012, em todo o Brasil. Na Paraíba esse aumento também é notado, passando do total de 14 prefeitas em 1993, para 27 no pleito de 2004. Em 2008 o total de eleitas na Paraíba foi de 34, e em 2012, 48 prefeitas. Mas quem são essas prefeitas paraibanas? É o que veremos agora.

No dia 03 de outubro de 2008 foram realizadas as eleições municipais para Prefeitos, Vice-Prefeitos e Vereadores em todos os municípios brasileiros. Dos 5.568 cargos executivos em disputa em todo o Brasil, apenas 505 foram ocupados por mulheres. Apesar de baixo, ainda é o maior índice se comparado as outras esferas governamentais. Na Paraíba, 34 mulheres foram eleitas, das quais 21 tentaram reeleição, sendo 15 reeleitas na eleição seguinte. Em 2012, o quantitativo de mulheres foi maior, atingindo um total de 662 prefeitas eleitas. No referido pleito, 48 mulheres foram eleitas para o executivo municipal na Paraíba.

Dessas 34 prefeitas eleitas em 2008, 50\% estão entre a faixa etária de 40 a 60 anos de idade. 25,5\%, entre 20 e 40 anos e 24,5\%, acima de 60 anos. Entre as eleitas em 2012, 40\% delas nasceram até 1960, ou seja, estão acima dos 50 anos de idade. 51\% tinham entre 30 e 50 anos de idade, e $9 \%$ tinham entre 20 e 30 anos. Blay (2015) aponta que as prefeitas eleitas na década de 1970 eram sua maioria mais jovens que os homens ocupando o mesmo cargo. Elas atingiram o chefia municipal na faixa etária de 36 e 55 anos. Consideradas um grupo de mulher "maduras", essa característica parece se perpetuar até os dias de hoje. Esse fato pode estar relacionado a uma série de fatores, como o caso da política ser considerado um campo que exige determinados conhecimentos, dessa forma, a maturidade seria algo necessário, já que o acúmulo de experiências poderia propor o acúmulo de capital político.

Quanto ao estado civil das gestoras municipais paraibanas, destacamos que das 34 eleitas em 2008, $57 \%$ delas eram casadas, seis viúvas e seis solteiras, somando 34\%, e 9\% separadas. Das 48 eleitas em 2012, $55 \%$ das gestoras são casadas, $11 \%$ divorciadas, $11 \%$ viúvas e $23 \%$ solteiras. Somando os demais status de estado civil, não se equiparam aquelas que se declararam casadas. O casamento, em pleno século XXI, ainda é considerado um fator determinante para o amadurecimento pessoal, principalmente se tratando do gênero feminino. Este é mais um indicativo de que a característica da maturidade faz parte do perfil das representantes 
femininas no poder municipal paraibano. Esse atributo não aparece particularmente no cenário paraibano, mas em toda cultura política brasileira, sendo considerado como algo que perpassa gerações. $\mathrm{O}$ estudo elaborado por Blay (2015) sobre as prefeitas na década de 1970 evidencia bem essa constatação. A mesma aponta que mais da metade das gestoras eleitas eram casadas.

Essa característica pode corroborar com um outro ponto bastante evidenciado quando se trata de analisar a representação feminina na política partidária. O casamento, fator constituidor de laços familiares, viria a colaborar com o processo de entrada de algumas mulheres na política. Lewin (1993) destaca a importância das redes familiares ou de parentela, como bases para a formação de redes de poder na Paraíba. Ainda referente a questão do familismo, ou parentela, Lewin (1993) destaca a necessidade da real compreensão de que a organização política paraibana desde o início da República, não se fundava exclusivamente em vínculos familiares de teor biológico, mas sim, em vínculos associativos à família, ou seja, para além do grau de parentesco, esse vínculo familiar também aglomerava a amizade política ou casamento. Para Lewin (1993), "a oligarquia da Paraíba espelhou uma combinação de fortes lealdades personalísticas e de recrutamento e mobilização familiar" (LEWIN, 1993, p. 21).

Outro ponto que chamaremos atenção diz respeito ao grau de instrução ou escolaridade das gestoras paraibanas. Tendo em vista que a educação foi uma das primeiras pautas de luta do grupo de mulheres que iniciaram os movimentos feministas e femininos aqui no Brasil, observamos que a grande maioria das mulheres eleitas para os mandados de 2008/2012 e 2012/2016, são portadoras de elevado grau de instrução. Das 34 eleitas em 2008, 73,5\%, possuem ensino superior; $14,5 \%$, possuem o ensino médio; $6 \%$, possuem o ensino fundamental completo. Completando o quadro, uma possui superior incompleto e uma o fundamental incompleto. Das 48 eleitas em 2012, 62\% possuem o ensino superior completo, $21 \%$ o ensino médio, 11\% o ensino fundamental completo, e $6 \%$ das prefeitas eleitas têm apenas o ensino fundamental incompleto.

Nesse ponto notamos uma mudança, se compararmos os dados referentes ao grau de escolaridade das prefeitas eleitas na década de 1970. Blay (2015) destaca que 50\% das eleitas em 1972 e 1976 não ultrapassavam o ensino primário. A mesma ainda ressalta que naquele contexto, os homens (prefeitos) tinham mais acesso ao ensino superior, ao contrário das mulheres (prefeitas). Blay (2015) argumenta que a escolaridade não é requisito levado em conta em determinadas localidades No tocante as prefeitas trabalhadas em sua pesquisa, a mesma afirma que "Elas se situam em posições ocupacionais e educacionais de nível médio, ao passo que os prefeitos desempenham ocupações de nível mais alto e atingem com mais frequência a educação superior" (BLAY, 2015 p. 33).

Percebemos e apontamos aqui uma mudança que pode ser entendida de forma positiva, levando em conta que por muitos séculos as mulheres foram excluídas dos processos educacionais, e quando inseridas, tratadas de forma diferenciada, tendo sua formação voltada para o âmbito privado. Esse alto percentual de prefeitas possuidoras de ensino superior é um indicativo de que as mulheres cada dia se fazem mais presentes das esferas educacionais, passo inicial para a emancipação feminina.

No que diz respeito a filiação partidária, os partidos que elegeram o maior número de prefeitos e prefeitas em todo o Brasil nas eleições de 2008 foi o PMDB, elegendo 1199 prefeitos/as, atingindo o percentual de 21,59\%. O segundo foi o PSDB com 790, 14 eleitos/as, o equivalente a 23\%. E o terceiro foi o PT conquistando 560 prefeituras, atingindo 10,08\% das prefeituras brasileiras. Na Paraíba, o PMDB também obteve êxito, conseguindo 59 prefeituras paraibanas, sendo 14 comandadas por mulheres. Os municípios governados por mulheres PMDBistas foram: Araruna, Barra de São Miguel, Bonito de Santa Fé, Conceição, Cuité, Cuité de Mamanguape, Damião, Guarabira, São José do Brejo do Cruz, Lagoa de Dentro, Pedras de Fogo, Rio Tinto, Santarém e São Domingos de Pombal. 
O PSDB conquistou 41 prefeituras na Paraíba, sendo 35 governadas por homens e 6 por mulheres. Os municípios comandas por mulheres PSDBistas foram: Areia de Baraúnas, Emas, Salgadinho, Uiraúna, Sobrado e Nova Olinda. O PT não obteve tanto êxito na Paraíba, conquistando apenas 6 prefeituras, 4 ocupadas por homens e 2 por mulheres, sendo elas: São Miguel de Taipú e Pombal. Outros partidos como o PHS (Alagoinha), DEM (Bananeiras, São José dos Ramos, Mato Grosso, Parari, Riachão do, Zabelê), PTB (Itabaiana, Jacaraú, Santana de Mangueira) e PP (Piancó e Pilar) também tiveram representantes femininas nas prefeituras paraibanas.

Na eleição municipal de 2012, novamente o PMDB foi o partido que mais elegeu prefeitos e prefeitas na Paraíba, atingindo um total de 41 prefeitos e 17 prefeitas. Os municípios comandados por mulheres PMDbistas são Araruna, Barra de São Miguel, Bonito de Santa Fé, Caldas Brandão, Cuité, Cuité de Mamanguape, Diamante, Joca Claudino, Logradouro, Matinhas, Patos, Rio Tinto, S. Domingos de Pombal, São José do Bonfim, São Sebastião de Lagoa de Roça, São Vicente do Seridó e Sertãozinho.

Em seguida temos o PSB (29 prefeitos e 5 prefeitas), o PSDB (23 prefeitos e 6 prefeitas), e o DEM (18 prefeitos e 4 prefeitas), somando um total de 14 prefeituras comandadas por mulheres em 2012. Estas são Cajazeiras, Desterro, Igaracy, Mulungu e Puxinanã do PSB; Areia de Baraúnas, Monteiro, Nova Olinda, Salgadinho, São Bentinho e São José do Sabugi do PSDB; e Monte Horebe, Poço de José de Moura, Serra da Raiz e Zabelê do DEM. Os demais municípios paraibanos governados por mulheres são Conde, Pilões e Santo André do PT do B; Juazeirinho e Santana de Mangueira do PTB; Brejo do Cruz do PR; Juarez Távora e Ouro Velho do PSD; Alagoinha do PHS; Pilar do PP; Mãe d'Água do PPS; Massaranduba do PSC; Borborema do PSF; Livramento e Pombal do PT.

Inicialmente tendo suas bandeiras de lutas enxergadas e abraçadas, em sua grande parte, por partidos de esquerda, o que vemos com os resultados apresentados acima, e quando comparados a outras localidade da região e do país, é que os partidos que mais elegem mulheres em nível municipal são aqueles considerados de direita ou do centro. Costa (1998) e Avelar (2001) e Blay (2015) destacam esse fato, e aponta-os como parte de estratégias desses partidos para se perpetuarem no poder.

Por fim, analisando o perfil populacional dos municípios que elegeram mulheres para o executivo municipal em 2008 e 2012, observou-se que, em sua maioria, são cidades de pequeno porte, e com um reduzido contingente populacional. Apontamos que 31 dos 48 municípios comandados por mulheres possuem menos de 10 mil habitantes. Isso demonstra que elas, ao menos no caso paraibano, se fazem presente nas cidades menos populosas do estado.

Também observou-se que dos 31 municípios com menos de 10 mil habitantes, 11 deles se emanciparam politicamente em 1994, possuindo pouco mais de 20 anos de municipalidade. Isso demonstra que além das prefeitas paraibanas governarem os municípios menos populosos, elas governam os mais jovens municípios do estado. São duas características muito importante, tendo em vista os empasses encontrados no processo de gestão de uma localidade, principalmente aquelas com pequeno porte, que carregam consigo características peculiares, como o baixo investimento financeiro e pouca circulação econômica.

Dessa forma, como característica que também marca o perfil das prefeitas paraibanas, vale destacar que a maioria das cidades comandadas por mulheres são consideradas cidades de pequeno porte, as menores em termos populacionais e também economicamente falando, o que pode nos levar a refletir sobre o porquê dessas mulheres estarem mais presentes nesses municípios "menos desenvolvidos", do Estado paraibano. A esse respeito, Blay (2015) afirma que "São as regiões de menor desenvolvimento econômico, menos urbanizadas e menos industrializadas as que mais elevam a mulher à chefia do poder local” (BLAY, 2015, p. 19). A 
socióloga ainda destaca que "o estudo de Costa (1998) para a Bahia e outros municípios do Nordeste brasileiro conclui que é maior o número de mulheres eleitas nos municípios pequenos e médios, nos quais as relações de poder permanecem sob controle das oligarquias" (BLAY, 2015, p. 67).

\section{Considerações}

Como mencionado acima, por muito tempo as mulheres estiveram a parte do mundo público, em especial da política partidária, segundo Bourdieu (2004), espaço constituído majoritariamente por homens, composto por regras de entrada e permanência. Ultrapassar barreiras estabelecidas por uma sociedade patriarcal talvez tenha sido o maior desafio encontrado pelo público feminino que ousou sair do espaço que lhes fora destinado, e buscou se fazer presente no mundo público.

O Brasil teve sua história eleitoral iniciada ainda no período colonial, sendo uma das mais antigas nações a fazer uso dessa prática, nem sempre aplicada de forma democrática e representativa. Exemplo disso é que por diferentes momentos, diversos grupos foram excluídos da participação política. As mulheres foram um desses, só conquistando o direito ao voto em 1932, durante o governo de Getúlio Vargas. Apesar de negado por parte da historiografia, esse fato é decorrente de profundas lutas e exigências sociais, encabeçadas principalmente pelos grupos de mulheres atuantes na época. O movimento Sufragista merece ser lembrado e ter sua importância ressaltada.

No decorrer do trabalho perpassamos por diferentes momentos da história política brasileira, nos quais as mulheres se fizeram presente, e contribuíram com a formação da cultura política brasileira. Nesse sentido, perpassamos também por diferentes práticas que comporam essa cultura política. Percebemos assim, como as mulheres estiveram presente e contribuíram com o processo de construção e perpetuação dessas diferentes práticas, e destacamos mais uma vez a ausência dessa discussão no campo historiográfico.

Dessa forma, pensando na representação, ou sub representação feminina na política partidária paraibana, observou-se que o quadro de gestoras é composto majoritariamente por mulheres com faixa etária acima dos 30 anos de idade, não ultrapassando os 60, maioria casadas e possuidoras de ensino superior completo. Destaca-se também que as mesmas governam, em especial, municípios menos desenvolvidos economicamente, emancipados recentemente, e com uma população inferior a 10.000 habitantes, tendo a maioria sido eleitas por partidos de direita e do centro. Esse panorama exposto, dialoga em diversos fatores apontados por Blay (2015) em sua pesquisa sobre as prefeitas eleitas na década de 1970. No livro As Prefeitas, ela apresenta as seguintes considerações.

Resumindo, pode-se dizer que as prefeitas são mulheres ora da pequena burguesia, ora provenientes de famílias latifundiárias. Chegam ao poder porque se diferenciam, na população de seus municípios, ou por sua origem de classe e dominação política, ou por suas atividades profissionais. Aquelas provenientes da oligarquia rural continuam a tradição familiar de deter a dominação do poder local. As demais chegam a este domínio através de uma popularização de suas pessoas e de suas ações por intermédio de suas ocupações. As profissionais tiveram contato com o público e ampliaram suas ações além do âmbito do próprio trabalho. As professoras, que servem de conselheiras enfermeiras, médicas, ou que colaboram com alunos e respectivos grupos familiares, se tornam pessoas a quem os beneficiados prestam o maior reconhecimento, o qual foi, no caso, expresso através das urnas. O mesmo raciocínio vale para outras profissões ou mesmo atividades assistenciais não remuneradas (BLAY, 2015, p. 37). 
Alguns desses apontamentos podem ser perfeitamente observados na representatividade feminina paraibana, demonstrando a perpetuação de algumas práticas e estratégias de grupos políticos. Para além das permanências, destaca-se também características "novas" compondo o perfil das gestoras eleitas nos últimos dois pleitos, 2008 e 2012 respectivamente. Isso é cultura política, é esse processo de permanência sem imutabilidade.

Dessa forma, longe de almejar esgotar a discussão sobre problemática, acreditamos ter trazido uma contribuição significante para os estudos da área. Compreender a representação feminina na política partidária faz parte de um exercício de entendimento da cidadania, tão comentada e pouco praticada no âmbito real.

\section{REFERÊNCIAS}

AVELAR, L., 2001. Mulheres na elite política brasileira. São Paulo: Centro de Estudos Konrad Adenauer Stifting.

BLAY, E., 2015. As prefeitas. Rio de Janeiro: Avenir Editora.

BOURDIEU, Pierre., 2004. O poder simbólico. Rio de Janeiro: Bertrand Brasil.

CARNEIRO, R. C., 2009. Cabresto, curral e peia: a história do voto na Parahyba até 1930. João Pessoa: Editora Universitária da UFPB.

COSTA, A. A. A., 1998. As donas no poder. Mulher e política na Bahia. Salvador: NEIM/UFBA.

GARCIA, C., 2005. As mulheres e as eleições municipais de 2004 no Nordeste. In: Cadernos feministas de economia \& política. Recife: Casa da Mulher do Nordeste, $n^{\circ} .2$.

GURJÃO, E. Q., 1994. Morte e Vida das Oligarquias-paraibanas: 1985-1945. João Pessoa: Ed. Universitária. UFPB.

1999. A Paraíba republicana: (1889 - 1930). In: EXTRUTURA DE PODER NA PARAÍBA.

SILVEIRA, Rosa Maria Godoy; GURJÃO, Eliete de Queiroz; ARAÚJO, Martha Lúci Ribeiro \& CITTADINO, Moniique. João Pessoa: Editora Universitária/UFPB.

LEWIN, L., 1993. Política e Parentela na Paraíba. Um Estudo de Caso da Oligarquia de Base Familiar. Rio de Janeiro: Record, 432 p.

MELLO, J. O. A., 1997. História da Paraíba. João Pessoa: Editora universitária/UFPB.

MORAES, M. L., 1985. Quartim de. Mulheres em movimento: o balanço da década de mulher do ponto de vista do feminismo, das religiões e da política. São Paulo: Nobel/CECF, p. 51

MOTTA, R. P. (org.), 2009. Cultura Política na História: novos estudos. Belo Horizonte: Argumentum/ FAPEMIG.

RABAY, G.; CARVAlHO, M. E. P., 2010. Mulher e Política na Paraíba. Histórias de vida e luta. João Pessoa: Assembleia Legislativa da Paraíba: Editora da UFPB.

RABAY, G.; CARVALHO, M; SILVA, M. B. 2013. As Prefeitas Paraibanas de 2013 a 2016.In: FAZENDO GÊNERO 10 - DESAFIOS ATUAIS DOS FEMINISMOS: Florianópolis, Anais eletrônicos do Fazendo Gênero 2010 - Desafios Atuais dos Feminismos: Florianópolis, UFSC, 2013. Disponível em: <http://www.fazendogenero.ufsc.br/10/resources/anais/20/1385662442_ARQUIVO_GloriaRabay.pdf>. Acesso em: 24 jan. 2016.

RÉMOND, R. (Org.), 1996. Por uma História Política. Tradução de Dora Rocha. Rio de Janeiro: FGV/ UFRJ. 
SILVEIRA, R. M. G., 2010. A $3^{\text {a }}$ Geração dos Annales: cultura histórica e memória. In: CURY, Cláudia Engler; FLORES, Elio Chaves; COORDEIRO JR, Raimundo Barroso (Orgs), Cultura Histórica e Historiografia: legados e contribuições do século 20. João Pessoa: Editora Universitária/UFPB, p. 37 a 68.

http://www.tse.jus.br/. Acesso em 10 de fev. de 2016.

http://www.tre.jus.br/. Acesso em 10 de fev. de 2016 